International Journal of

Environmental Research and

Public Health

ISSN 1660-4601

www.mdpi.com/journal/ijerph

Article

\title{
Emissions of Escherichia coli Carrying Extended-Spectrum $\beta$-Lactamase Resistance from Pig Farms to the Surrounding Environment
}

\author{
Lili Gao ${ }^{1,2,3, \dagger}$, Yeke Tan ${ }^{4, \dagger}$, Xiaodan Zhang ${ }^{1,2,3, \dagger}$, Jiaqing Hu ${ }^{1}$, Zengmin Miao ${ }^{5}$, \\ Liangmeng Wei ${ }^{1,2,3, *}$ and Tongjie Chai ${ }^{1,2,3, *}$
}

1 College of Veterinary Medicine, Shandong Agricultural University, Tai'an 271000, Shandong, China; E-Mails: abigheart@163.com (L.G.); zhangxiaodan89@126.com (X.Z.); hujiaqing0609@126.com (J.H.)

2 Sino-German Cooperative Research Centre for Zoonosis of Animal Origin Shandong Province, Tai'an 271000, Shandong, China

3 Key Laboratory of Animal Biotechnology and Disease Control and Prevention of Shandong Province, Tai'an 271000, Shandong, China

4 Tai'an City Central Hospital, Tai'an 271000, Shandong, China; E-Mail: tykaaa@163.com

5 College of Life Sciences, Taishan Medical University, Tai'an 271000, China;

E-Mail: Zengminmiao@163.com

$\dagger$ These authors contributed equally to this work.

* Authors to whom correspondence should be addressed; E-Mails: 1mwei@sdau.edu.cn (L.W.); chaitj117@163.com (T.C.); Tel.: +86-538-824-8114 (T.C.); Fax: +86-538-824-1419 (T.C.).

Academic Editor: Oladele A. Ogunseitan

Received: 6 March 2015 / Accepted: 9 April 2015 / Published: 16 April 2015

Abstract: The dissemination of extended-spectrum $\beta$-lactamase (ESBL)-producing Escherichia coli (E. coli) from food-producing animals to the surrounding environment has attracted much attention. To determine the emissions of ESBL-producing E. coli from pig farms to the surrounding environment, fecal and environmental samples from six pig farms were collected. In total, 119 ESBL-producing E. coli were isolated from feces, air samples, water, sludge and soil samples. Antibiotic susceptibility testing showed that the ESBL-producing isolates were resistant to multiple antibiotics and isolates of different origin within the same farm showed similar resistance phenotypes. Both CTX-M and TEM 
ESBL-encoding genes were detected in these isolates. CTX-M-14 and CTX-M-15 were the predominant ESBL genes identified. ESBL producers from feces and environmental samples within the same farm carried similar CTX-M types. The results indicated that the ESBL-producing E. coli carrying multidrug resistance could readily disseminate to the surrounding environment.

Keywords: ESBL-producing E. coli; environment; emission; CTX-M

\section{Introduction}

The increasing prevalence of extended-spectrum $\beta$-lactamases (ESBLs) in the World has attracted wide attention [1]. ESBLs are enzymes that can destroy $\beta$-lactam antibiotics, including penicillins, first, second and third-generation cephalosporins and aztreonam which are susceptible to $\beta$-lactamase inhibitors [2]. The ability of ESBLs to confer bacterial resistance can dramatically decrease therapeutic options in disease control and treatment $[3,4]$. The ESBL enzymes mainly include three types, TEM, SHV and CTX-M [5]. Since first discovered in 1989 [6], CTX-M gene has become the most common ESBL enzyme and has spread quickly throughout the World taking the place of TEM and SHV types that were prevalent in the early 1990s [5]. Genes encoding these various ESBL genes are located on mobile genetic elements and could disseminate through horizontal gene transfer between bacteria, and even between different species [7].

Food-producing animals were considered reservoirs of zoonotic pathogens and resistant bacteria [8]. Escherichia coli can survive in the gastrointestinal tract of food-producing animals as a commensal bacterium and can also cause infections [9]. Extended-spectrum cephalosporins are effective drugs against such infections in veterinary clinical use; which creates a selective pressure for ESBL-producing E. coli. Animals colonized with ESBL-producing E. coli have been considered as potential sources of resistant $E$. coli infections in the community, which has attracted wide concern [10]. Furthermore; the ESBL-producing E. coli in animal farms could influence public health through environment pollution and contaminated animal products [11].

The dissemination of these resistant bacteria from animal houses through various routes exerts pressure on the surrounding environment and even influences the living environment of human beings. Aerosol transmission is an important route for virus and bacteria [12]. E. coli has been identified to transmit through air by aerosol formation [13]. Aerosol transmission of ESBL-producing E. coli with air flow contributes to its dissemination. The discharge of waste products and farmland application of effluents and feces could also promote the entry of drug-resistant bacteria into the environment [14]. To date, ESBL-producing bacteria have been found in various environments, where they may be a reservoir contributing to the spread of resistant bacteria [14,15]. In this study, to estimate the transmission of ESBL-producing E. coli originated from pig farms to the surrounding environment, ESBL-producing E. coli was collected from fecal and environmental samples from pig farms in China. 


\section{Materials and Methods}

\subsection{Pig Farms}

Six pig farms located in different regions of Shandong Province, China and their surrounding environments were selected to collect samples to investigate the transmission of ESBL-producing E. coli from food animal-producing houses to the surrounding environment. ESBL-producing $E$. coli has been found in six (A, B, C, D, E and F) out of ten pig farms in our primary research. These farms are far away from villages. Negative pressure ventilation was used in these farms.

\subsection{Sampling}

Fecal and environmental samples were collected from these farms between April 2013 and June 2013 to evaluate the spread of resistant bacteria produced in pig farms to the surrounding environment. Air samples were collected using a six-stage Anderson sampler [16] at an airflow rate of $28.3 \mathrm{~L} / \mathrm{min}$ placed at a height of $1.0 \mathrm{~m}$ indoors and outdoors in the down- and upwind positions as previously reported [13]. Each time, six MacConkey agar plates with $2 \mu \mathrm{g} / \mathrm{mL}$ cefotaxime were used as medium placed in an Anderson six-stage sampler for air sample collection. Inside and outside air samples were collected at the same time. In each house, inside air samples were collected at three locations along the passage with a time of 20-30 min. Outside air samples were collected at different distances including $10 \mathrm{~m}$ and $50 \mathrm{~m}$ upwind, and $10 \mathrm{~m}, 50 \mathrm{~m}$, and $100 \mathrm{~m}$ downwind. No air samples were collected from farms $\mathrm{E}$ and $\mathrm{F}$.

At the same time, environmental samples were collected. Water and sludge were collected in the vicinity of pig farms A, B, C and D. River water samples were collected at $10 \mathrm{~m}$ upstream, and $10 \mathrm{~m}$, $50 \mathrm{~m}$ and $100 \mathrm{~m}$ downstream away from the drain outlet. Sludge samples were collected at the outlet of the effluent. Soil samples were collected at different directions outside of the animal house. These samples were transferred to an ice box and then processed immediately upon arrival at the lab.

\subsection{Cefotaxime-Resistant E. coli Isolation}

After collection, the MacConkey agar plates with $2 \mu \mathrm{g} / \mathrm{mL}$ cefotaxime used for air samples were incubated at $37{ }^{\circ} \mathrm{C}$ overnight directly. Fecal samples were serially diluted twice with sterile phosphate buffered saline solution and then $100 \mu \mathrm{L}$ was cultured on MacConkey agar plates with $2 \mu \mathrm{g} / \mathrm{mL}$ cefotaxime and incubated overnight. The river water samples were filtered using a nitrocellulose membrane filter and then the filter was placed on agar plates. Soil and sludge samples (2 g) were transferred into $50 \mathrm{~mL}$ Luria-Bertani (LB) broth for enrichment. Following bacteria enrichment, overnight cultures were streaked on MacConkey agar plates with $2 \mu \mathrm{g} / \mathrm{mL}$ cefotaxime at $37{ }^{\circ} \mathrm{C}$ overnight. One or two colonies with typical $E$. coli morphology were selected and further streaked on LB agar plates for purification. Presumptive pure cultures were identified by classical biochemical methods and the API 20E system [17].

\subsection{Confirmation and Antimicrobial Susceptibility Testing}

The $E$. coli isolates from feces and environmental samples were subjected to a double disk diffusion method for confirmation of the ESBL-producing E. coli using ceftazidime or cefotaxime, alone or together 
with clavulanic acid. The antimicrobial susceptibility of the $E$. coli isolates was tested by the disk diffusion method on Mueller-Hinton agar plates using the following antibiotics: ampicillin (AMP, $10 \mu \mathrm{g}$ ), amoxicillin/clavulanic acid (AMC, $20 \mu \mathrm{g}+10 \mu \mathrm{g}$ ), piperacillin/tazobactam (TZP, $100 \mu \mathrm{g}+10 \mu \mathrm{g}$ ), ampicillin/salbactam (SAM, $10 \mu \mathrm{g}+10 \mu \mathrm{g}$ ), cephalothin (CF, $30 \mu \mathrm{g}$ ), cefuroxime (CXM, $30 \mu \mathrm{g})$, aztreonam (ATM, $30 \mu \mathrm{g}$ ), ciprofloxacin (CIP, $5 \mu \mathrm{g}$ ), norfloxacin (NOR, $10 \mu \mathrm{g}$ ), gentamicin (GM, $10 \mu \mathrm{g}$ ), tetracycline (TE, $30 \mu \mathrm{g})$, streptomycin $(\mathrm{S}, 10 \mu \mathrm{g})$, chloramphenicol $(\mathrm{C}, 30 \mu \mathrm{g})$, kanamycin $(\mathrm{K}$, $30 \mu \mathrm{g}$ ), nalidixic acid (NA, $30 \mu \mathrm{g}$ ), trimethoprim/sulfamethoxazole (SXT, $25 \mu \mathrm{g}$ ) and trimethoprim (TMP, $5 \mu \mathrm{g}$ ) according to CLSI [18]. The E. coli ATCC 25922 was used for quality control.

\subsection{Resistance Genes}

TEM-, SHV-, and CTX-M-encoding ESBL genes were identified using multiplex polymerase chain reactions (PCR) to determine the ESBL types of the ESBL producing E. coli from different samples, as previously described [19]. TEM-encoding genes were further amplified as described previously [20] and the amplicons were sequenced. The bla СтХ-м genes were further amplified and analyzed using group primers CTX-M-1, CTX-M-2, CTX-M-8 and CTX-M-9, as described previously [21,22]. The PCR products were purified and cloned in $\mathrm{pMD}-18 \mathrm{~T}$ for sequencing. The obtained DNA sequences were compared and blasted (http://www.ncbi.nlm.nih.gov/) to confirm the $\beta$-lactamase gene subtype.

\subsection{Statistical Analysis}

Pearson's chi-square test was used to compare the continuous data. The association between resistance phenotype of isolates from fecal and environmental samples were evaluated. Correlation coefficients ( $r$ values) and the levels of significance ( $p$ values) were used to interpret the results of correlation analyses. Two-tailed $\mathrm{p}$ values of 0.05 were considered statistically significant. The statistical analyses were conducted using the statistics software, SPSS, version 19.0 (IBM SPSS, Chicago, IL, USA).

\section{Results}

\subsection{Samples Positive for ESBL-Producing E. coli from Feces and Environments}

One hundred and twenty samples positive for ESBL-producing E. coli were detected from the fecal samples from the six farms. Water and sludge samples were collected from A, B, C and D farms. In the vicinity of E and F farm, no river was found. Samples positive for ESBL producers were detected in air samples in three out of four pig farms.

ESBL positive water samples were found in all the four pig farms with collected water samples. Of the sludge samples, samples positive for ESBL-producing E. coli were found in farm A, B and D. Soil samples were collected from all six farms. On farm E, planting soil samples were also collected as the soil was amended with feces from the farm. ESBL-positive samples were only found in planting soil samples from farm $\mathrm{E}$ and two from surface soil in farm $\mathrm{F}$ (Table 1). 
Table 1. No. of samples (total) and ESBL-positive samples (+) from six pig farms.

\begin{tabular}{|c|c|c|c|c|c|c|c|c|c|c|}
\hline \multirow{2}{*}{ Farms } & \multicolumn{2}{|c|}{ No of Feces } & \multicolumn{2}{|c|}{ No. of Air Samples } & \multicolumn{2}{|c|}{ No. of Water Samples } & \multicolumn{2}{|c|}{ No. of Sludge Samples } & \multicolumn{2}{|c|}{ Soil Samples } \\
\hline & Total & + & Total & + & Total & + & Total & + & Total & + \\
\hline $\mathrm{A}$ & 30 & 5 & 8 & 0 & 10 & 1 & 5 & 2 & 10 & 0 \\
\hline B & 30 & 10 & 8 & $3 / 3$ & 10 & 2 & 5 & 2 & 10 & 0 \\
\hline $\mathrm{C}$ & 30 & 10 & 8 & 1 & 10 & 3 & 5 & 0 & 10 & 0 \\
\hline $\mathrm{D}$ & 30 & 16 & 8 & 2 & 10 & 2 & 5 & 1 & 10 & 0 \\
\hline $\mathrm{E}$ & 40 & 32 & - & - & - & - & - & - & 80 & 10 \\
\hline $\mathrm{F}$ & 40 & 13 & - & - & - & - & - & - & 20 & 2 \\
\hline
\end{tabular}

\subsection{Isolation and Identification of ESBL-Producing E. coli}

A total of 120 cefotaxime-resistant $E$. coli strains were isolated from fecal samples and environmental samples collected from the six pig farms. One hundred and nineteen E. coli isolates from feces, indoor air samples and outdoor air samples, water and sludge samples and soil samples were confirmed to be ESBL-producing E. coli after the phenotypic confirmatory test. In three out of six pig farms (B, C and D), ESBL-producing E. coli were detected in air samples (six, one and two, respectively). Seven ESBL-producing E. coli were obtained from water samples outside the four farms, and five from sludge samples. A total of 12 ESBL-producers were isolated from soil samples.

From farm A, five isolates were obtained from feces, one came from water (10 $\mathrm{m}$ downstream), and two were isolated from sludge samples. Among the 20 ESBL-producing E. coli isolated from farm B, 10 isolates were from feces, six were from air samples including three indoor air isolates and three outdoor air isolates from $10 \mathrm{~m}$ and $100 \mathrm{~m}$ downwind, and four were from water (10 $\mathrm{m}$ downstream) and sludge samples. In farm C, two water isolates from $10 \mathrm{~m}$ downstream and one from $50 \mathrm{~m}$ downstream, and one ESBL-producing isolates from an indoor air sample, outdoor air sample (10 m downwind), water and sludge sample respectively were obtained (Table 2).

Table 2. No. of 119 ESBL-producing E. coli and their locations.

\begin{tabular}{cccc}
\hline Farm & Samples & No. of ESBL Producers & Locations \\
\hline \multirow{2}{*}{ Farm A } & Feces & 5 & \\
& Water samples & 1 & $10 \mathrm{~m}$ downstream \\
& Sludge samples & 2 & \\
& Feces & 10 & $10 \mathrm{~m}$ downwind \\
& Indoor air samples & 3 & $100 \mathrm{~m}$ downwind \\
Farm B & Outdoor air samples & 3 & $10 \mathrm{~m}$ downstream \\
& Water samples & 2 & \\
& Sludge samples & 2 & $10 \mathrm{~m}$ downstream \\
\multirow{2}{*}{ Farm C } & Feces & 10 & $50 \mathrm{~m}$ downstream \\
\hline
\end{tabular}


Table 2. Cont.

\begin{tabular}{cccc}
\hline Farm & Samples & No. of ESBL Producers & Locations \\
\hline \multirow{4}{*}{ Farm D } & Feces & 16 & \\
& Indoor air samples & 1 & 10 m downwind \\
& Outdoor air samples & 1 & $10 \mathrm{~m}$ downstream \\
& Water samples & 1 & \\
& Sludge samples & 1 & \\
\multirow{2}{*}{ Farm E } & Feces & 32 & Amended soil \\
\hline \multirow{2}{*}{ Farm F } & Soil samples & 10 & \\
& Feces & 13 & \\
\hline
\end{tabular}

\subsection{Antimicrobial Susceptibility Testing}

All the ESBL-producing E. coli from the six pig farms were susceptible to AMC, TZP, SAM and TMP, but resistant to AMP and $\mathrm{CF}$, and highly resistant to PRL and TE. Isolates from $\mathrm{B}, \mathrm{D}$ and $\mathrm{F}$ were all resistant to ATM. For other antibiotics, different resistance phenotypes were obtained from these ESBL producers between these six farms. High resistance to GM, S and K was observed in farms B, D, $\mathrm{E}$ and F. The ESBL-producers from different farms also showed different resistance levels to CIP, NA, SXT and C. Significant associations in resistance rate were observed between isolates from feces and environmental samples within the same farm (Table 3).

Table 3. Resistance to 17 antibiotics of the 119 ESBL-producing E. coli isolates. Fecal isolates, FI; Environmental isolates, EI. $p<0.01$.

\begin{tabular}{|c|c|c|c|c|c|c|c|c|c|c|c|c|}
\hline \multirow[t]{2}{*}{ Antibiotics } & \multicolumn{2}{|c|}{$\begin{array}{c}\text { Farm A } \\
(\mathrm{n}=\mathbf{8})\end{array}$} & \multicolumn{2}{|c|}{$\begin{array}{l}\text { Farm B } \\
(\mathbf{n}=\mathbf{2 0})\end{array}$} & \multicolumn{2}{|c|}{$\begin{array}{l}\text { Farm } C \\
(n=14)\end{array}$} & \multicolumn{2}{|c|}{$\begin{array}{l}\text { Farm D } \\
(\mathbf{n}=\mathbf{2 0}) \\
\end{array}$} & \multicolumn{2}{|c|}{$\begin{array}{l}\text { Farm } E \\
(n=42)\end{array}$} & \multicolumn{2}{|c|}{$\begin{array}{l}\text { Farm F } \\
(n=15)\end{array}$} \\
\hline & FI & EI & FI & EI & FI & EI & FI & EI & FI & EI & FI & EI \\
\hline AMP & 100 & 100 & 100 & 100 & 100 & 100 & 100 & 100 & 100 & 100 & 100 & 100 \\
\hline $\mathrm{CF}$ & 100 & 100 & 100 & 100 & 100 & 100 & 100 & 100 & 100 & 100 & 100 & 100 \\
\hline PRL & 100 & 67 & 50 & 30 & 90 & 75 & 63 & 50 & 94 & 80 & 85 & 100 \\
\hline CXM & 60 & 100 & 80 & 80 & 30 & 0 & 100 & 75 & 100 & 100 & 92 & 100 \\
\hline ATM & 0 & 0 & 100 & 100 & 0 & 0 & 100 & 100 & 94 & 80 & 100 & 100 \\
\hline AMC & 0 & 0 & 0 & 0 & 0 & 0 & 0 & 0 & 0 & 0 & 0 & 0 \\
\hline $\mathrm{TZP}$ & 0 & 0 & 0 & 0 & 0 & 0 & 0 & 0 & 0 & 0 & 0 & 0 \\
\hline SAM & 0 & 0 & 0 & 0 & 0 & 0 & 0 & 0 & 0 & 0 & 0 & 0 \\
\hline $\mathrm{GM}$ & 0 & 0 & 70 & 60 & 30 & 25 & 63 & 75 & 44 & 60 & 85 & 50 \\
\hline $\mathrm{K}$ & 20 & 0 & 90 & 70 & 10 & 0 & 100 & 75 & 69 & 70 & 92 & 100 \\
\hline $\mathrm{S}$ & 0 & 0 & 60 & 60 & 40 & 75 & 63 & 50 & 81 & 70 & 54 & 50 \\
\hline TMP & 0 & 0 & 0 & 0 & 0 & 0 & 0 & 0 & 0 & 0 & 0 & 0 \\
\hline $\mathrm{TE}$ & 60 & 33 & 100 & 80 & 90 & 75 & 100 & 100 & 91 & 90 & 85 & 0 \\
\hline CIP & 20 & 0 & 70 & 80 & 10 & 0 & 44 & 50 & 53 & 10 & 23 & 0 \\
\hline NA & 80 & 67 & 90 & 80 & 40 & 25 & 81 & 75 & 56 & 10 & 23 & 0 \\
\hline SXT & 0 & 33 & 100 & 80 & 80 & 100 & 56 & 50 & 84 & 60 & 92 & 100 \\
\hline $\mathrm{C}$ & 20 & 33 & 70 & 60 & 90 & 100 & 88 & 75 & 91 & 70 & 100 & 0 \\
\hline $\mathrm{r}$ & \multicolumn{2}{|c|}{0.892} & \multicolumn{2}{|c|}{0.971} & \multicolumn{2}{|c|}{0.944} & \multicolumn{2}{|c|}{0.969} & \multicolumn{2}{|c|}{0.914} & \multicolumn{2}{|c|}{0.752} \\
\hline
\end{tabular}




\subsection{ESBL Gene}

TEM and CTX-M genes were detected in all ESBL-producing isolates from the six pig farms. However, no SHV gene was found. In these pig farms, five kinds of CTX-M subtypes were detected including bla $a_{\mathrm{CTX}-\mathrm{M}-14,}$ bla $a_{\mathrm{CTX}-\mathrm{M}-15,}$ bla $a_{\mathrm{CTX}-\mathrm{M}-24}$, bla $a_{\mathrm{CTX}-\mathrm{M}-27}$ and bla ${ }_{\mathrm{CTX}-\mathrm{M}-65}$. The diversity of CTX-M genes of ESBL-producing isolates from feces and environmental samples tended to be similar, however, the prevalent CTX-M types and kinds of subtypes varied between farms.

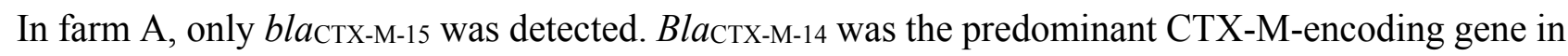
farm B $(\mathrm{n}=7)$, followed by bla $a_{\text {CTX-M-24 }}(\mathrm{n}=3)$, bla $a_{\text {CTX-M-15 }}(\mathrm{n}=2)$, bla $a_{\text {CTX-M-27 }}(\mathrm{n}=2)$, and bla ${ }_{\text {CTX-M- } 65}$

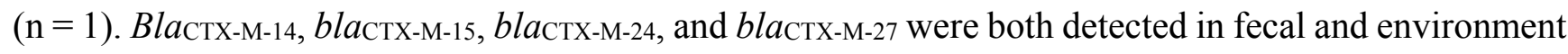
original ESBL-producing E. coli. In farm C, blacтХ-М-14 and blacтХ-М-15 were both detected in fecal and environmental isolates except blactХ-М-27. Among the three kinds of blacтХ-м detected, blactХ-М-14 was the predominant CTX-M type that both detected in feces and environmental samples. In farms E and F, the predominant CTX-M type was blacтХ-M-15, followed by bla СтХ-М-14 in fecal and environmental samples. BlactХ-м-27 and bla (Table 4).

Table 4. $\beta$-Lactamase genes in the phenotypic detected ESBL-producing $E$. coli from fecal and environmental samples. Fecal isolates, FI; Environmental isolates, EI.

\begin{tabular}{|c|c|c|c|c|c|c|c|c|c|c|c|c|}
\hline \multirow[t]{2}{*}{ Genes } & \multicolumn{2}{|c|}{$\begin{array}{c}\text { Farm A } \\
(n=8)\end{array}$} & \multicolumn{2}{|c|}{$\begin{array}{l}\text { Farm B } \\
(n=20)\end{array}$} & \multicolumn{2}{|c|}{$\begin{array}{l}\text { Farm C } \\
(\mathrm{n}=14)\end{array}$} & \multicolumn{2}{|c|}{$\begin{array}{l}\text { Farm D } \\
(n=20)\end{array}$} & \multicolumn{2}{|c|}{$\begin{array}{c}\text { Farm E } \\
(n=42)\end{array}$} & \multicolumn{2}{|c|}{$\begin{array}{l}\text { Farm F } \\
(n=15)\end{array}$} \\
\hline & FI & EI & FI & EI & FI & EI & FI & EI & FI & $\overline{\text { EI }}$ & $\overline{\text { FI }}$ & $\overline{\text { EI }}$ \\
\hline CTX-M-14 & - & - & 6 & 1 & 4 & 2 & 6 & 1 & 5 & 3 & 3 & 1 \\
\hline CTX-M-15 & 4 & 2 & 1 & 1 & - & - & - & - & 12 & 3 & 7 & 1 \\
\hline CTX-M-24 & - & - & 1 & 2 & - & - & - & - & - & - & - & - \\
\hline CTX-M-27 & - & - & 1 & 1 & 3 & - & 2 & - & 7 & - & 2 & - \\
\hline CTX-M-65 & - & - & - & 1 & 2 & 1 & 2 & 1 & 7 & 1 & - & - \\
\hline CTX-M & 4 & 2 & 9 & 6 & 9 & 3 & 10 & 2 & 31 & 7 & 12 & 2 \\
\hline CTX-M/TEM & 3 & 2 & 4 & 4 & 5 & 0 & 4 & 0 & 26 & 6 & 8 & 1 \\
\hline TEM-1 & 4 & 3 & 5 & 8 & 6 & 1 & 10 & 2 & 26 & 9 & 9 & 1 \\
\hline
\end{tabular}

\section{Discussion}

With the use of antibiotics, more and more resistant bacteria occur in food-producing animals, including ESBL-producing E. coli. The spread of these bacteria through various routes to the environment creates a threat to public health. In this study, ESBL-producing E. coli was isolated from feces and environment samples including indoor air, outdoor air, water and sludge samples and soil samples from six pig farms in rural regions of Shandong, China. From the six farms, ESBL-producing E. coli was all detected in feces and different kinds of environmental samples, which indicated the possible transmission routes of ESBL-producers from food-producing animal farms.

All 119 of the ESBL-producing isolates from fecal and environmental samples showed high rates of resistance to multiple antimicrobial agents. Isolates showing resistance to two or more classes of drugs were treated as multi-drug resistant (MDR). The resistance profiles varied between different farms, but 
were highly related between isolates from feces and environmental samples within the same farm. These results suggested that the ESBL-producers in the environment might originate from the pig farm.

The CTX-M gene was the predominant ESBL gene in this region, consistent with previous reports [23]. Bla $\mathrm{CTX-M-14}$ and bla $\mathrm{CTX}_{\mathrm{CT}-15}$ were the most common CTX-M type, similar to what has been reported in pigs, cattle, and chickens [11,24]. Various CTX-M subtypes were detected, including

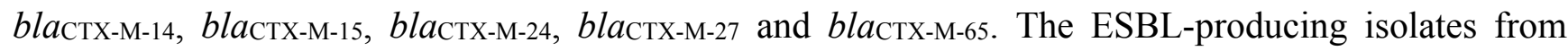
feces and environmental samples within the same farm tend to carry the same kind of CTX-M gene, while the diversity of CTX-M subtypes varied between different pig farms.

In food-producing animal production, high concentrations of airborne microorganisms are often found in indoor environments [25]. These microbes in such an environment can survive in the form of aerosols for a long time in the air and transmit with air flow [13]. In this study, ESBL-producing E. coli was obtained from the indoor air and outdoor air samples. Isolates from indoor, outdoor and fecal samples showed high similarity, which indicated the airborne transmission of the ESBL-producing E. coli in pig farms. Previous studies had demonstrated the dissemination of ESBL-producing $E$. coli originated from chicken houses into the air [26,27]. The concentrations of microorganisms were closely related with the air quality. A poor air environment could benefit the spread of ESBL-producing E. coli.

ESBL-producing bacteria have been increasingly reported in water and sludge [28-30]. Agricultural use of contaminated water or sludge could be a possible route for ESBL-producing E. coli to enter into the food chain [31,32]. In this study, ESBL-producing E. coli were also isolated from river water and sludge samples, which shared similar resistance profiles and ESBL genes with fecal isolates within the same farm. These results suggested the potential influence of pig farms on the surrounding water environments.

In conclusion, the high similarities of isolates from environmental and fecal samples suggest a possible dissemination of resistant bacteria from pig feces into the surrounding environment. These results indicated the emissions of resistant $E$. coli isolates from pig houses to the surrounding environment, which constitutes a major threat to public health. As the origin of resistant bacteria, thus the rational use and antibiotics and the establishment of effective management of food-producing animal farms are necessary.

\section{Conclusions}

Comparison of isolation rates, resistance profiles and $\beta$-lactamase genes showed that fecal isolates and environmental isolates shared similar characteristics, which suggested the possible emissions of the ESBL-producing E. coli from feces to the environment.

\section{Acknowledgments}

This study was sponsored by the NSFC project (31270172) and (31470258); The National Science and Technology Support Project (2012BAD39B0205); Open Fund 2013 of the State Key Laboratory for Environmental Protection, Using of Environmental Microbiology and Security Controls (SMARC2013D001). 


\section{Author Contributions}

Tongjie Chai Zengmin Miao and Lili Gao designed this study. Lili Gao, Xiaodan Zhang and Jiaqing $\mathrm{Hu}$ took samples. Lili Gao and Xiaodan Zhang performed the bacterial isolation, microbiological experiments, and analyses. Liangmeng Wei and Tongjie Chai revised this manuscript.

\section{Conflicts of Interest}

The authors declare no conflict of interest.

\section{References}

1. Pitout, J.D.; Laupland, K.B. Extended-spectrum beta-lactamase-producing Enterobacteriaceae: An emerging public-health concern. Lancet Infect. Dis. 2008, 8, 159-166.

2. Malloy, A.M.; Campos, J.M. Extended-spectrum beta-lactamases: A brief clinical update. Pediatr. Infect. Dis. J. 2011, 30, 1092-1093.

3. Ewers, C.; Stamm, I.; Pfeifer, Y.; Wieler, L.H.; Kopp, P.A.; Schonning, K.; Prenger-Berninghoff, E.; Scheufen, S.; Stolle, I.; Gunther, S.; et al. Clonal spread of highly successful ST15-CTX-M-15 Klebsiella pneumoniae in companion animals and horses. J. Antimicrob. Chemother. 2014, 69, 2676-2680.

4. Paterson, D.L.; Bonomo, R.A. Extended-spectrum beta-lactamases: A clinical update. Clin. Microbiol. Rev. 2005, 18, 657-686.

5. Canton, R.; Coque, T.M. The CTX-M beta-lactamase pandemic. Curr. Opin. Microbiol. 2006, 9 , 466-475.

6. Bauernfeind, A.; Grimm, H.; Schweighart, S. A new plasmidic cefotaximase in a clinical isolate of Escherichia coli. Infection 1990, 18, 294-298.

7. Knothe, H.; Shah, P.; Krcmery, V.; Antal, M.; Mitsuhashi, S. Transferable resistance to cefotaxime, cefoxitin, cefamandole and cefuroxime in clinical isolates of Klebsiella pneumoniae and Serratia marcescens. Infection 1983, 11, 315-317.

8. Carattoli, A. Animal reservoirs for extended spectrum beta-lactamase producers. Clin. Microbiol. Infect. 2008, 14, 117-123.

9. Blanc, V.; Mesa, R.; Saco, M.; Lavilla, S.; Prats, G.; Miro, E.; Navarro, F.; Cortes, P.; Llagostera, M. ESBL- and plasmidic class $\mathrm{C}$ beta-lactamase-producing $E$. coli strains isolated from poultry, pig and rabbit farms. Vet. Microbiol. 2006, 118, 299-304.

10. Smet, A.; Martel, A.; Persoons, D.; Dewulf, J.; Heyndrickx, M.; Herman, L.; Haesebrouck, F.; Butaye, P. Broad-spectrum beta-lactamases among Enterobacteriaceae of animal origin: Molecular aspects, mobility and impact on public health. FEMS Microbiol. Rev. 2010, 34, 295-316.

11. Horton, R.A.; Randall, L.P.; Snary, E.L.; Cockrem, H.; Lotz, S.; Wearing, H.; Duncan, D.; Rabie, A.; McLaren, I.; Watson, E.; et al. Fecal carriage and shedding density of CTX-M extended-spectrum \{beta\}-lactamase-producing Escherichia coli in cattle, chickens, and pigs: Implications for environmental contamination and food production. Appl. Environ. Microbiol. 2011, 77, 3715-3719. 
12. Aliabadi, A.A.; Rogak, S.N.; Bartlett, K.H.; Green, S.I. Preventing airborne disease transmission: Review of methods for ventilation design in health care facilities. Adv. Prev. Med. 2011, 2011, doi:10.4061/2011/124064.

13. Yuan, W.; Chai, T.J.; Miao, Z.M. ERIC-PCR identification of the spread of airborne Escherichia coli in pig houses. Sci. Total Environ. 2010, 408, 1446-1450.

14. Hartmann, A.; Locatelli, A.; Amoureux, L.; Depret, G.; Jolivet, C.; Gueneau, E.; Neuwirth, C. Occurrence of CTX-M producing Escherichia coli in soils, cattle, and farm environment in France (Burgundy Region). Front. Microbiol. 2012, 3, doi:10.3389/fmicb.2012.00083.

15. Jang, J.; Suh, Y.S.; Di, D.Y.; Unno, T.; Sadowsky, M.J.; Hur, H.G. Pathogenic Escherichia coli strains producing extended-spectrum beta-lactamases in the Yeongsan River basin of South Korea. Environ. Sci. Technol. 2013, 47, 1128-1136.

16. Andersen, A.A. New sampler for the collection, sizing, and enumeration of viable particles. J. Bacteriol. 1958, 76, 471-484.

17. Poeta, P.; Radhouani, H.; Goncalves, A.; Figueiredo, N.; Carvalho, C.; Rodrigues, J.; Igrejas, G. Genetic characterization of antibiotic resistance in enteropathogenic Escherichia coli carrying extended-spectrum beta-lactamases recovered from diarrhoeic rabbits. Zoonoses Public Health 2010, 57, 162-170.

18. CLSI. Performance Standards for Antimicrobial Susceptibility Testing; Eighteenth Informational Supplement; CLSI Document M100-S18; Clinical and Laboratory Standards Institute: Wayne, PA, USA, 2011.

19. Monstein, H.J.; Ostholm-Balkhed, A.; Nilsson, M.V.; Nilsson, M.; Dornbusch, K.; Nilsson, L.E. Multiplex PCR amplification assay for the detection of blaSHV, blaTEM and blaCTX-M genes in Enterobacteriaceae. APMIS 2007, 115, 1400-1408.

20. Olesen, I.; Hasman, H.; Aarestrup, F.M. Prevalence of beta-lactamases among ampicillin-resistant Escherichia coli and Salmonella isolated from food animals in Denmark. Microb. Drug Resist. 2004, 10, 334-340.

21. Batchelor, M.; Hopkins, K.; Threlfall, E.J.; Clifton-Hadley, F.A.; Stallwood, A.D.; Davies, R.H.; Liebana, E. Bla(CTX-M) genes in clinical Salmonella isolates recovered from humans in England and Wales from 1992 to 2003. Antimicrob. Agents Chemother. 2005, 49, 1319-1322.

22. Woodford, N.; Fagan, E.J.; Ellington, M.J. Multiplex PCR for rapid detection of genes encoding CTX-M extended-spectrum (beta)-lactamases. J. Antimicrob. Chemother. 2006, 57, 154-155.

23. Guo, Y.F.; Zhang, W.H.; Ren, S.Q.; Yang, L.; Lu, D.H.; Zeng, Z.L.; Liu, Y.H.; Jiang, H.X. IncA/C plasmid-mediated spread of CMY-2 in multidrug-resistant Escherichia coli from food animals in China. PLoS ONE 2014, 9, doi:10.1371/journal.pone.0096738.

24. Liu, B.T.; Li, L.; Fang, L.X.; Sun, J.; Liao, X.P.; Yang, Q.E.; Huang, T.; Liu, Y.H. Characterization of plasmids carrying oqxAB in blaCTX-M-negative Escherichia coli Isolates from food-producing animals. Microb. Drug Resist. 2014, 20, 641-650.

25. Fallschissel, K.; Klug, K.; Kampfer, P.; Jackel, U. Detection of airborne bacteria in a German turkey house by cultivation-based and molecular methods. Ann. Occup. Hyg. 2010, 54, 934-943.

26. Li, S.; Zhao, M.Q.; Li, Y.L.; Zhang, L.; Zhang, X.Z.; Miao, Z.M. Detection and source identification of airborne extended-spectrum beta-lactamase-producing Escherichia coli isolates in a chicken house. Aerobiologia 2013, 29, 315-319. 
27. Laube, H.; Friese, A.; von Salviati, C.; Guerra, B.; Rosler, U. Transmission of ESBL/AmpC-producing Escherichia coli from broiler chicken farms to surrounding areas. Vet. Microbiol. 2014, 172, 519-527.

28. Blaak, H.; de Kruijf, P.; Hamidjaja, R.A.; van Hoek, A.H.; de Roda Husman, A.M.; Schets, F.M. Prevalence and characteristics of ESBL-producing E. coli in Dutch recreational waters influenced by wastewater treatment plants. Vet. Microbiol. 2014, 171, 448-459.

29. Reinthaler, F.F.; Feierl, G.; Galler, H.; Haas, D.; Leitner, E.; Mascher, F.; Melkes, A.; Posch, J.; Winter, I.; Zarfel, G.; Marth, E. ESBL-producing E. coli in Austrian sewage sludge. Water Res. 2010, 44, 1981-1985.

30. Zheng, H.; Zeng, Z.; Chen, S.; Liu, Y.; Yao, Q.; Deng, Y.; Chen, X.; Lv, L.; Zhuo, C.; Chen, Z.; et al. Prevalence and characterisation of CTX-M beta-lactamases amongst Escherichia coli isolates from healthy food animals in China. Int. J. Antimicrob. Agents 2012, 39, 305-310.

31. Dolejska, M.; Frolkova, P.; Florek, M.; Jamborova, I.; Purgertova, M.; Kutilova, I.; Cizek, A.; Guenther, S.; Literak, I. CTX-M-15-producing Escherichia coli clone B2-O25b-ST131 and Klebsiella spp. isolates in municipal wastewater treatment plant effluents. J. Antimicrob. Chemother. 2011, 66, 2784-2790.

32. Lu, S.Y.; Zhang, Y.L.; Geng, S.N.; Li, T.Y.; Ye, Z.M.; Zhang, D.S.; Zou, F.; Zhou, H.W. High diversity of extended-spectrum beta-lactamase-producing bacteria in an urban river sediment habitat. Appl. Environ. Microbiol. 2010, 76, 5972-5976.

(C) 2015 by the authors; licensee MDPI, Basel, Switzerland. This article is an open access article distributed under the terms and conditions of the Creative Commons Attribution license (http://creativecommons.org/licenses/by/4.0/). 